\title{
Effect of biomaterials hydrophobicity and roughness on biofilm development
}

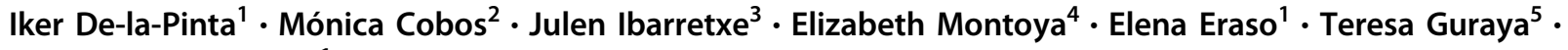 \\ Guillermo Quindós (1)
}

Received: 9 April 2019 / Accepted: 10 June 2019 / Published online: 19 June 2019

(c) Springer Science+Business Media, LLC, part of Springer Nature 2019

\begin{abstract}
Most hospitalized patients are carriers of biomedical devices. Infections associated with these devices cause great morbidity and mortality, especially in patients in intensive care units. Numerous strategies have been designed to prevent biofilm development on biodevices. However, biofilm formation is a complex process not fully clarified. In the current study, roughness and hydrophobicity of different biomaterials was analyzed to assess their influences on the biofilm formation of four leading etiological causes of healthcare-associated infections, Escherichia coli, Pseudomonas aeruginosa, Staphylococcus epidermidis and Candida albicans, using a CDC biofilm reactor. Hydrophobic materials allowed the formation of more abundant and profuse biofilms. Roughness had effect on biofilm formation, but its influence was not significant when material hydrophobicity was considered.
\end{abstract}

\section{Graphical Abstract}

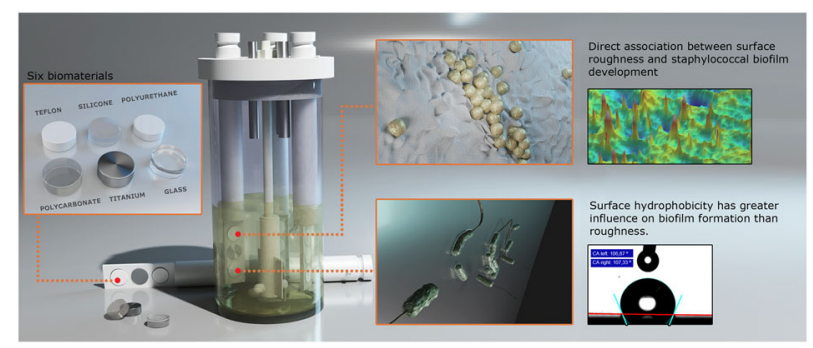

Guillermo Quindós guillermo.quindos@ehu.eus

1 Departamento de Inmunología, Microbiología y Parasitología, UFI 11/25, Facultad de Medicina y Enfermería, Universidad del País Vasco/Euskal Herriko Unibertsitatea UPV/EHU, Bilbao, Spain

2 Departamento de Ciencia y Tecnología de Polímeros, Facultad de Química, Universidad del País Vasco/Euskal Herriko Unibertsitatea UPV/EHU, San Sebastián, Spain

3 Departamento de Física aplicada I, Escuela de Ingeniería de Bilbao, Universidad del País Vasco/Euskal Herriko Unibertsitatea UPV/EHU, Bilbao, Spain

4 Leartiker Polymer R\&D, Leartiker, Markina-Xemein, Spain

5 Departamento de Ingeniería Minera y Metalúrgica y Ciencia de los Materiales, Escuela de Ingeniería de Bilbao, Universidad del País Vasco/Euskal Herriko Unibertsitatea UPV/EHU, Bilbao, Spain

\section{Introduction}

There were an estimated 687,000 healthcare-associated infections (HAI) in 2015 at the United States and about 72,000 hospital patients died from them during their hospitalizations [1]. In the European Union, more than 4,000,000 patients suffer from HAI every year [2]. Many HAI are related to biofilm development on biomedical devices, such as ventilator-associated pneumonia, catheter-associated urinary tract infections or surgical-site infections [3].

Teflon, titanium, polyurethane, silicone, polycarbonate or borosilicate glass are current components of medical and surgical devices colonized during HAIs [4-7]. Surface hydrophobicity and roughness of these biomaterials play important roles in the initial microbial adhesion and the subsequent biofilm formation by Staphylococcus epidermidis, Escherichia coli, Pseudomonas aeruginosa or 
Candida albicans, causing recalcitrant infections to treatment [8]. However, there is still no agreement on how biomaterials hydrophobicity and roughness determine biofilm development.

To the best of our knowledge, this is the first study that analyzes the influence of both properties, roughness and hydrophobicity, on bacterial biofilm development on biomedical devices by means of the CDC Biofilm Reactor (CBR), a reproducible model for studying biofilm simulating factors and forces that undergo biofilms in dynamics humanized environments under body flows [9].

\section{Materials and methods}

\subsection{Study design}

The current study was performed in two phases. In the first phase, the effect of generating different superficial roughness in polyurethane disks on $S$. epidermidis biofilm development was evaluated, while in the second phase, the hydrophobicity and roughness of six different biomaterials were characterized in order to determine their influence on biofilm by means of the CBR with four microorganisms.

\subsection{Microorganisms}

Three well-described bacterial species and one clinically relevant yeast were used: E. coli ATCC 25922, P. aeruginosa ATCC 27853, S. epidermidis ATCC 35984 and $C$. albicans NCPF 3153. Microorganisms were stored at $-80{ }^{\circ} \mathrm{C}$ on cryoballs (Microbank, Biolab Diagnostics, Canada). During the assay, microorganisms were cultured in brain-heart infusion (BHI) medium and grown overnight at $37^{\circ} \mathrm{C}$ in an orbital incubator. Cultures were centrifuged at $3000 \mathrm{rpm}$ for $10 \mathrm{~min}$, and washed twice in phosphatebuffered saline (PBS). Inoculum was adjusted at 0.5 McFarland $\left(\sim 1-5 \times 10^{8} \mathrm{CFU} / \mathrm{ml}\right.$ for bacteria and $1-5 \times$ $10^{6} \mathrm{CFU} / \mathrm{ml}$ for $C$. albicans).

\subsection{CDC biofilm reactor (CBR)}

Biofilms were developed in CBR 90-1 (BioSurface Technologies Corp., Bozeman, MT, USA) as described by Goeres et al. [10]. CBR consisted of a one-liter glass vessel with a polyethylene top that supports eight independent and removable polypropylene rods. Each rod holds three removable disks used as surfaces for biofilm development (Fig. 1). One milliliter of inoculum was injected into the reactor containing $0.3 \mathrm{~g}$ of tryptic soy broth (TSB) per liter for $E$. coli and $P$. aeruginosa, $30 \mathrm{~g} / \mathrm{l}$ of TSB for $S$. epidermidis or yeast extract peptone dextrose (YEPD) broth for C. albicans. CBR stood on a digital stir plate set at $37 \pm$
$1{ }^{\circ} \mathrm{C}$ and $120 \mathrm{rpm}$ for inducing a fluid shear onto the disk surfaces.

\subsection{Disks and disk cleaning procedure}

The biofilm growth surface consisted of disks of different materials with a diameter of $1.27 \mathrm{~cm}$ and a height of $0.3 \mathrm{~cm}$. Commercially available titanium, polycarbonate, silicone, borosilicate and Teflon disks were obtained from BioSurface Technologies Corp. Disks were sterilized and sonicated according to the standard ASTM E2562-16 [11]. Sterile polyurethane disks were manufactured by Leartiker, S. Coop (Markina-Xemein, Spain).

Polyurethane disks were grinded using a semi-automated grinding-polishing machine (Tegrapol-11/Tegraforce-1, Struers Inc, Cleveland, OH, USA). Surface roughness preparation was controlled using grinding $\mathrm{SiC}$ papers with several grits (320, 800, 1200 and 4000). Fixed times and forces were used for each sandpaper, and roughness was measured to check that resulting surface had the same roughness. Afterward polyurethane disks were sterilized using ethylene oxide.

\subsection{Roughness and hydrophobicity measurements}

Surface roughness was determined by a Leica dual core 3D microscope Leica DCM 3D (Leica Microsystems, L'Hospitalet de Llobregat, Spain) analyzing a surface of $2 \mathrm{~mm} \times$ $1.2 \mathrm{~mm}$ by the Leica Map DCM 3D software $[12,13]$. The parameters $\mathrm{Sa}, \mathrm{Sq}, \mathrm{Sz}, \mathrm{Ssk}$, Sku and Str were calculated (UNE ISO, 25178-2:2013) [14]. Sa is the arithmetical mean height of the surface. Sq is the root mean square height of the surface. $\mathrm{Sz}$ is the maximum height of the surface. Ssk is the degree of symmetry of the surface heights about the mean plane (skewness). Sku is a measure of the sharpness of the roughness profile (kurtosis). Finally, Sdr or developed interfacial area ratio is the percentage of additional surface area contributed by the texture as compared to an ideal plane the size of the measurement region. The Sdr of a completely level surface is zero being a hybrid parameter affected by both texture amplitude (peaks height) and spacing.

Contact angle, commonly used to evaluate the surface hydrophobicity, was determined using a goniometer (OCA 15EC, Dataphysics, Filderstadt, Germany). Briefly, droplets of distilled water were placed in both faces of the disks and ten readings of different areas were taken to determine average values for each disk. Drop shape image was processed by an image analysis system (SCA software, Dataphysics, Filderstadt, Germany) that calculated both left and right contact angles from the shape of the drop with an accuracy of $\pm 0.1^{\circ}$.

Cell surface hydrophobicity was assessed by the microbial adhesion assay to hydrocarbons (MATH) described by 
Fig. $1 \mathrm{CDC}$ biofilm reactor over the digital hot/stir plate

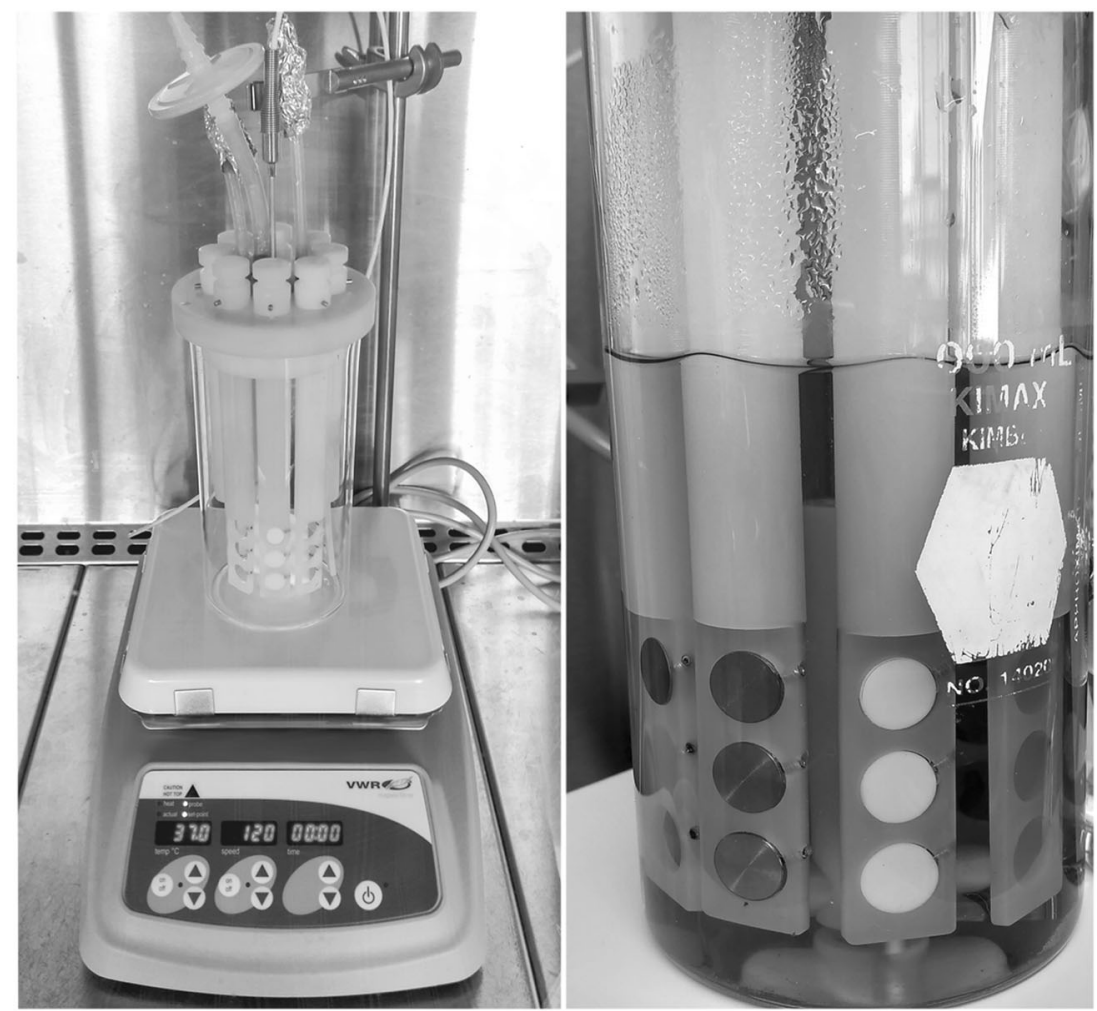

Rosenberg et al. [15] based on the percentage decrease in absorbance of the lower aqueous phase when adding hexadecane to a bacterial suspension in PBS. According to Krepsky et al. [16], strains considered highly hydrophobic had values $>50 \%$, and those moderately hydrophobic ranged from $>20$ to $<50 \%$. Hydrophilic surfaces were those whose values were under $20 \%$.

\subsection{Quantification of biofilm biomass}

Three disks of each material were removed from the CBR. Disks were rinsed in PBS to remove planktonic cells and placed into tubes containing $25 \mathrm{ml}$ of PBS. Biofilm detachment was carried out by $30 \mathrm{~s}$ of vortex mixing, 2 min of sonication (VCX 130, Sonics Materials, USA) at $50 \%$ of amplitude followed by $30 \mathrm{~s}$ of vortex mixing. Resulting cell suspensions were sequentially diluted and $100 \mu \mathrm{l}$ were plated onto PCA plates or onto SDA plates for yeast. Plates were incubated for $24 \mathrm{~h}$ at $37 \pm 1{ }^{\circ} \mathrm{C}$.

\subsection{Data analysis}

Biofilm burden was presented as mean of the logarithm of colony-forming units (CFU) per $\mathrm{cm}^{2}$ of material. Data were analyzed using analysis of variance (ANOVA) followed by Bonferroni or Games-Howell's correction depending on the homogeneity of variances (Levene test) and significant differences were determined $(p<0.05)$. The statistical software
SPSS 24 (IBM SPSS Statistic, Chicago, USA) was used. All assays were performed at least in triplicate and experiments were repeated at least three times at different days.

\section{Results}

\subsection{Influence of roughness in biofilm formation by $S$. epidermidis}

\subsubsection{Characterization of surface roughness and hydrophobicity of polyurethane disks}

Original disk showed the lowest roughness $(\mathrm{Sa}=0.34 \mu \mathrm{m})$. The grinding of the disks with different grit numbers was used to modify their roughness. The lowest grit number produced a higher roughness (320 grit, $\mathrm{Sa}=1.90 \mu \mathrm{m})$, while the highest grit number resulted in a smoother surface (4000 grit, $\mathrm{Sa}=0.38 \mu \mathrm{m})$. 3D roughness reconstruction of grinded disks is shown in Fig. 2. By modifying the roughness of the material, the contact angle is also affected, decreasing its wettability (Table 1).

\subsubsection{Biofilm formed by S. epidermidis on polyurethane disks}

Roughness affected S. epidermidis biofilm burden only in grinded disks (Fig. 3). The smallest biofilm burden with a 
A

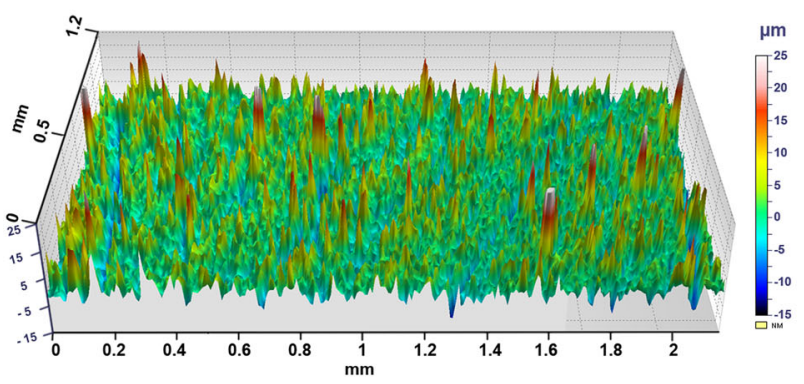

C

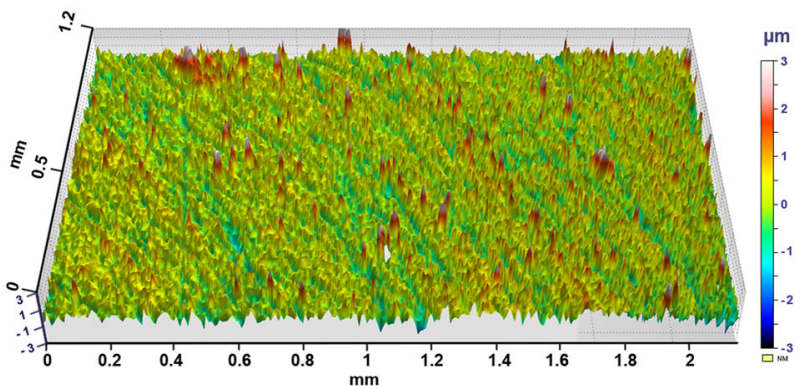

B

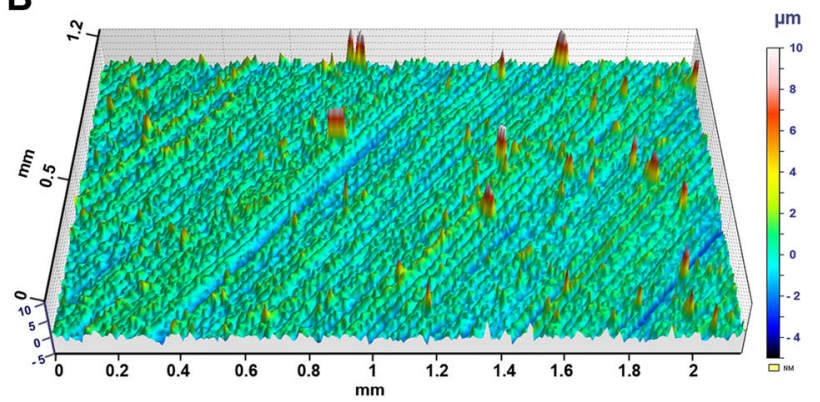

D

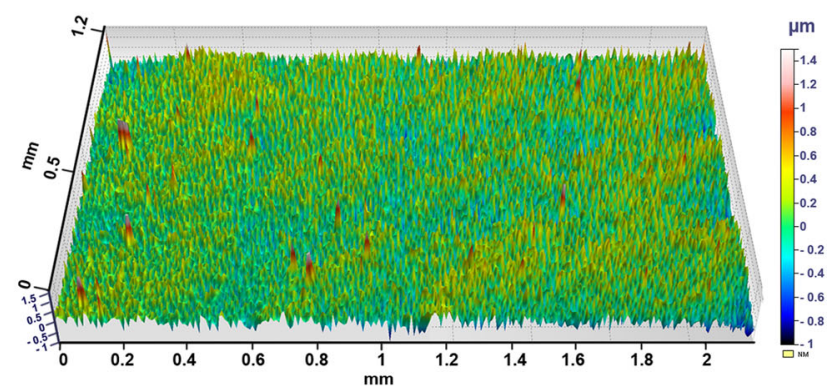

Fig. 2 3D roughness reconstruction of grinded disks. a Surface of disks grinded with 320 grit SiC paper. b Surface of disks grinded with 800 grit $\mathrm{SiC}$ paper. c Surface of disks grinded with 1200 grit SiC paper. d Surface of disks grinded with 4000 grit SiC paper

Table 1 Surface roughness parameters and contact angle of unmodified and grinded disks

\begin{tabular}{llllrrrrr}
\hline Grit size & Sa $(\mu \mathrm{m})$ & Sq $(\mu \mathrm{m})$ & Sz $(\mu \mathrm{m})$ & \multicolumn{1}{c}{ Ssk } & Sku & Sdr $(\%)$ & $\begin{array}{l}\text { Contact angle }\left(^{\circ}\right), \\
\theta Y\end{array}$ & $\begin{array}{l}\text { Contact angle }\left(^{\circ}\right), \\
\theta \mathrm{m}\end{array}$ \\
\hline W/o grinding & 0.34 & 0.46 & 24.6 & -1.85 & 24.54 & 1.87 & $103.84 \pm 0.93$ & $103.58 \pm 0.91$ \\
320 & 1.88 & 2.46 & 22.08 & -0.16 & 4.11 & 14.68 & $130.09 \pm 2.80$ & $124.15 \pm 2.24$ \\
800 & 1.08 & 1.51 & 19.79 & 0.97 & 9.36 & 9.76 & $130.89 \pm 3.59$ & $126.59 \pm 3.09$ \\
1200 & 0.51 & 0.66 & 9.27 & -0.24 & 5.00 & 3.43 & $119.05 \pm 1.76$ & $118.00 \pm 1.69$ \\
4000 & 0.38 & 0.59 & 8.52 & 2.10 & 19.09 & 1.94 & $108.41 \pm 4.48$ & $108.04 \pm 4.39$ \\
\hline
\end{tabular}

ISO 25178 height parameters. Sa: arithmetic average of the value of the height. Sq: root mean square height of the surface. Sz: maximum height of the surface (maximum height of the peaks + maximum height of the valleys). Ssk: degree of symmetry of the surface heights about the mean plane (skewness). Sku: measure of the sharpness of the roughness profile (kurtosis). $\theta \mathrm{Y}$ expresses the measured contact angle and $\theta \mathrm{m}$ expresses the theoretically contact angle in a flat surface

logarithm of bacterial density of $6.65(p=0.010)$ was observed on the disk with the lowest roughness $(\mathrm{Sa}=$ $0.38 \mu \mathrm{m})$. Higher biofilm formation was on the disk with the highest roughness $(\mathrm{Sa}=1.88 \mu \mathrm{m})$ with a logarithm of 7.45 $(p=0.009)$. However, there were no significant differences in biofilm between disks with intermediate roughness $(\mathrm{Sa}=$ $0.51 \mu \mathrm{m}$ and $1.08 \mu \mathrm{m}, p=1.000)$. Interestingly, the original disk without grinding (roughness $0.34 \mu \mathrm{m}$ ) was not the surface with the least biofilm formed.

Structure and differences in S. epidermidis biofilm distribution in all grinded disks were confirmed by SEM. Representative images of staphylococcal adhesion on grinded surfaces are shown in Fig. 4. The disks grinded with 320 and 800 grit papers showed long and deep grooves along entire surface. In contrast, disks grinded with 1200 and 4000 grit sandpapers showed a smoother surface. There were biofilms with a significant network of matrix on all disks, being more numerous on those ones with rougher surfaces. Staphylococcal adhesion and biofilm development were influenced by surface texture of polyurethane, as increased bacterial adhesion and larger bacterial aggregates were observed on the roughest patterned surfaces. Larger amounts of biofilm were found on the disks grinded with 320 grit paper compared to the disks grinded with 4000 grit paper. Biofilms after $48 \mathrm{~h}$ showed extracellular polymeric substances and 3D mushroom-like structures. Biofilms were distributed in clusters all over the surface of the disks, but large microbial clusters were observed at edges (Fig. 4). Higher concentration of biofilm at the edges of disks could be associated with the fact that CBR bar where the discs are placed could protect these edges from broth shear force, allowing a greater bacterial accumulation. 


\subsection{Influence of hydrophobicity in biofilm formation}

\subsubsection{Characterization of surface roughness and hydrophobicity}

Surface roughness and contact angles of all materials tested were determined. Sa surface roughness was within the range of $0.03-3.81 \mu \mathrm{m}$ and their contact angles between $20^{\circ}$ and $112^{\circ}$ (Table 1). Biomaterials were categorized in four groups

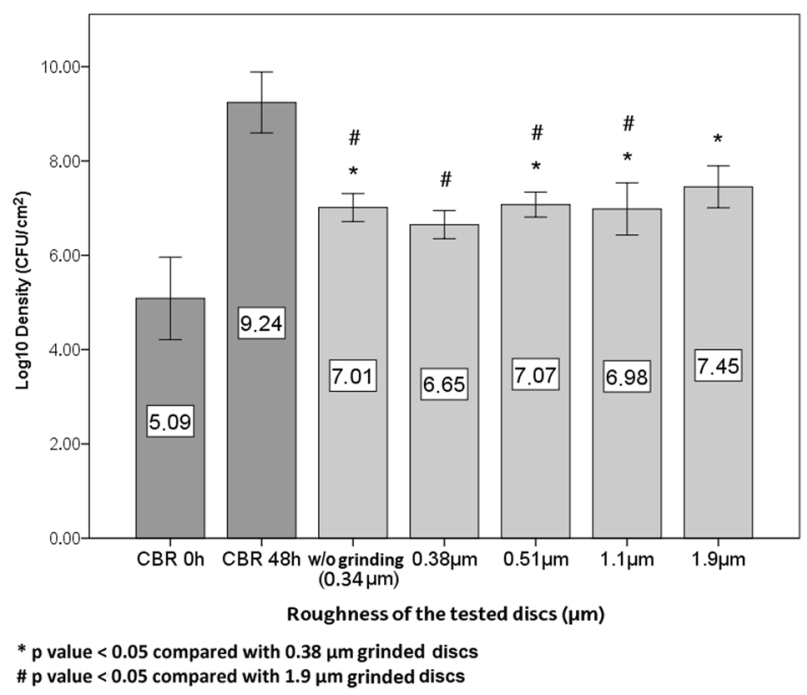

Fig. 3 Biofilm formed according to different roughness. Dark grey bars represent the planktonic growth in the CDC biofilm reactor at $0 \mathrm{~h}$ and $48 \mathrm{~h}$. Light grey bars represent the biofilm produced by $S$. epidermidis ATCC 35984 on polyurethane disks after $48 \mathrm{~h}$ according to their roughness, being Teflon $(\mathrm{Sa}=3.81 \mu \mathrm{m})$ the roughest, followed by polycarbonate $(\mathrm{Sa}=0.96 \mu \mathrm{m})$. Titanium and polyurethane showed an intermediate roughness. Silicone $(\mathrm{Sa}=0.08 \mu \mathrm{m})$ and borosilicate glass $(\mathrm{Sa}=0.03 \mu \mathrm{m})$ showed the lowest surface roughness (Table 2, Fig. 5).

Biomaterials could be divided in four groups according to their hydrophobicity, being Teflon and silicone $(p=0.670)$ the most hydrophobic materials, followed by polyurethane with no statistical differences with silicone $(p=0.597)$. Polycarbonate and titanium had less hydrophobicity $(p=$ 0.000). Finally, borosilicate was quite hydrophilic $(p=0.000)$. Interestingly, the roughest material was also the most hydrophobic, just as the least rough was the least hydrophobic too. However, silicone was just as hydrophobic as Teflon and showed a very low roughness, below $0.1 \mu \mathrm{m}$ (Table 2).

\subsubsection{Microbial adherence to N-hexadecane test (MATH)}

S. epidermidis and $P$. aeruginosa, with a hydrophobicity of $56.6 \%$ and $66.6 \%$, respectively, showed medium-high levels of cell surface hydrophobicity (Fig. 6). Conversely, E. coli $(0.93 \%)$ and C. albicans (12.63\%) displayed a very low hydrophobicity.

\subsubsection{Biofilm formation}

Teflon, the roughest and most hydrophobic material, is where most bacterial biofilm was produced, along with silicone. Conversely, borosilicate, the least rough and

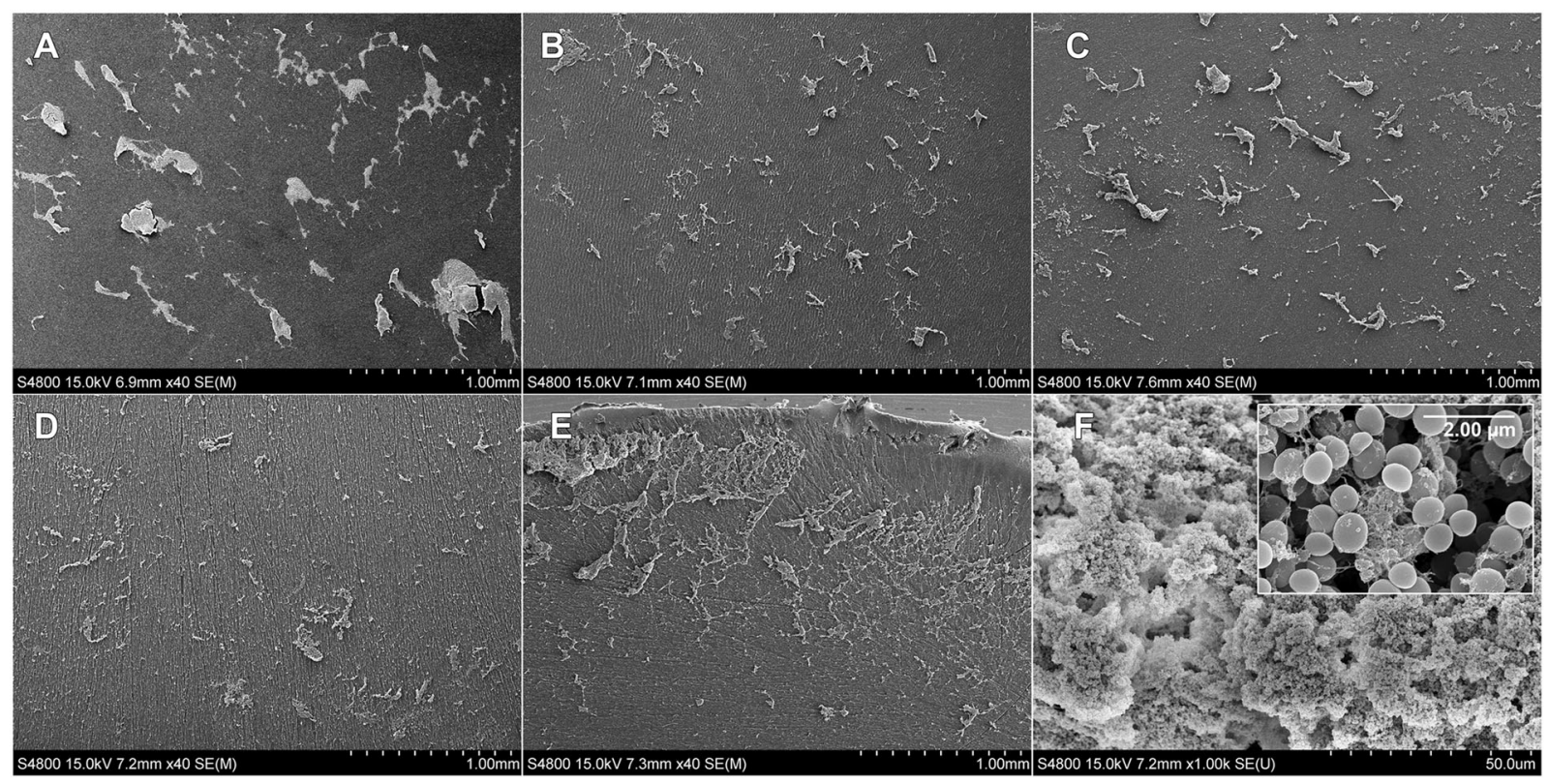

Fig. 4 Scanning electron microscopy of biofilm on the surface of polyurethane disks with different roughness. a Without grinding. b Grinded with 4000 grit SiC paper. c Grinded with 1200 grit SiC paper. d Grinded with 800 grit $\mathrm{SiC}$ paper. e Grinded with 320 grit $\mathrm{SiC}$ paper. f $S$. epidermidis and extracellular polymeric matrix 
Table 2 Surface roughness parameters of the different disks measured by $3 \mathrm{D}$ microscope Leica DCM 3D and sorted by their hydrophobicity

\begin{tabular}{|c|c|c|c|c|c|c|}
\hline \multirow[t]{2}{*}{ Biomaterial } & \multicolumn{5}{|c|}{ Roughness parameters } & \multirow{2}{*}{$\begin{array}{l}\text { Hydrophobicity } \\
\text { Contact angle }\left({ }^{\circ}\right)\end{array}$} \\
\hline & $\mathrm{Sa}(\mu \mathrm{m})$ & $\mathrm{Sq}(\mu \mathrm{m})$ & $\mathrm{Sz}(\mu \mathrm{m})$ & Ssk & $\mathrm{Sku}$ & \\
\hline Teflon & 3.81 & 5.04 & 35.33 & -0.60 & 4.51 & $111.64 \pm 5.15$ \\
\hline Silicone & 0.08 & 0.11 & 1.12 & -1.59 & 8.47 & $108.05 \pm 2.69$ \\
\hline Polyurethane & 0.34 & 0.46 & 24.61 & -1.85 & 24.54 & $103.84 \pm 0.93$ \\
\hline Polycarbonate & 0.96 & 1.22 & 10.18 & -0.15 & 3.34 & $76.63 \pm 7.02$ \\
\hline Titanium & 0.29 & 0.36 & 2.53 & 0.07 & 3.40 & $55.18 \pm 19.63$ \\
\hline Borosilicate glass & 0.03 & 0.07 & 0.76 & 5.87 & 52.91 & $20.88 \pm 4.82$ \\
\hline
\end{tabular}

ISO 25178 height parameters. Sa: arithmetic average of the value of the height. Sq: root mean square height of the surface. Sz: maximum height of the surface (maximum height of the peaks + maximum height of the valleys). Ssk: degree of symmetry of the surface heights about the mean plane (skewness). Sku: measure of the sharpness of the roughness profile (kurtosis)
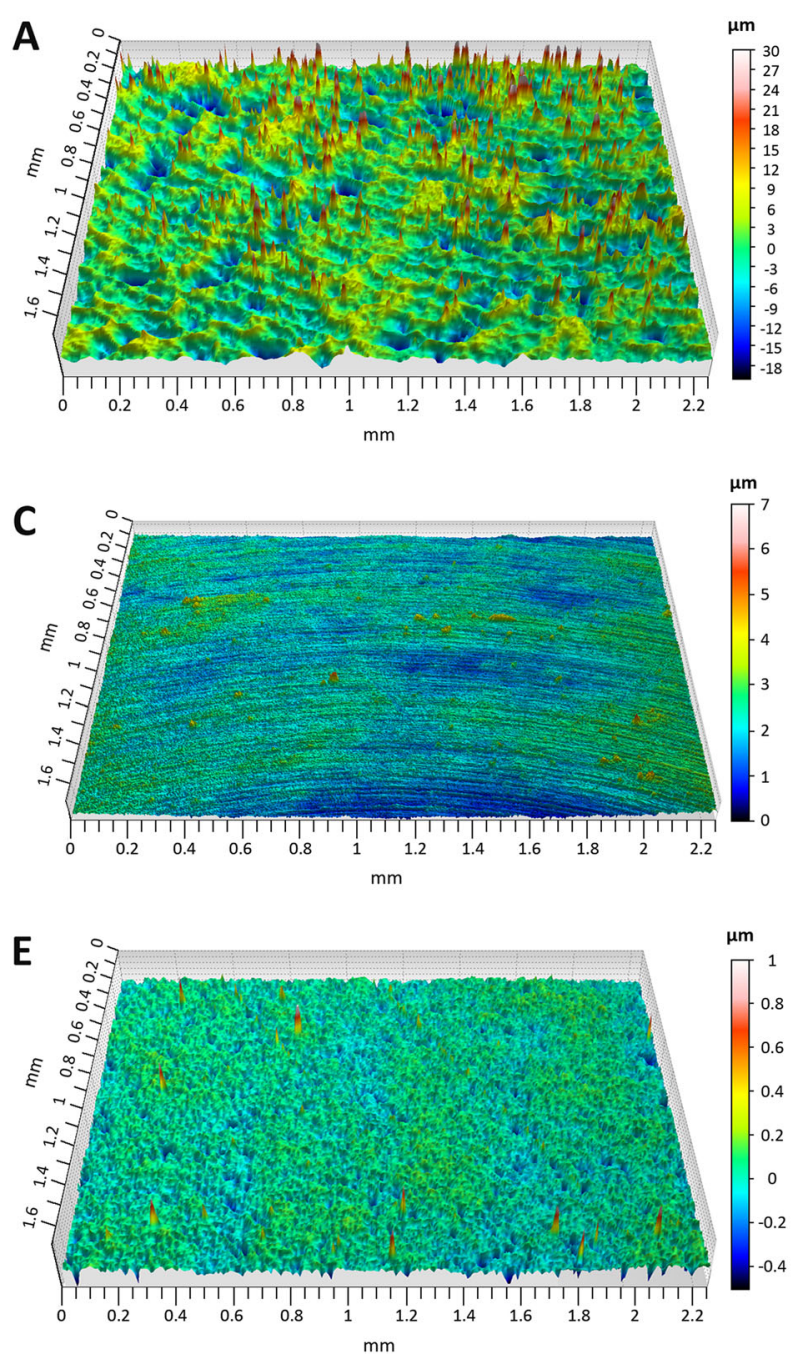
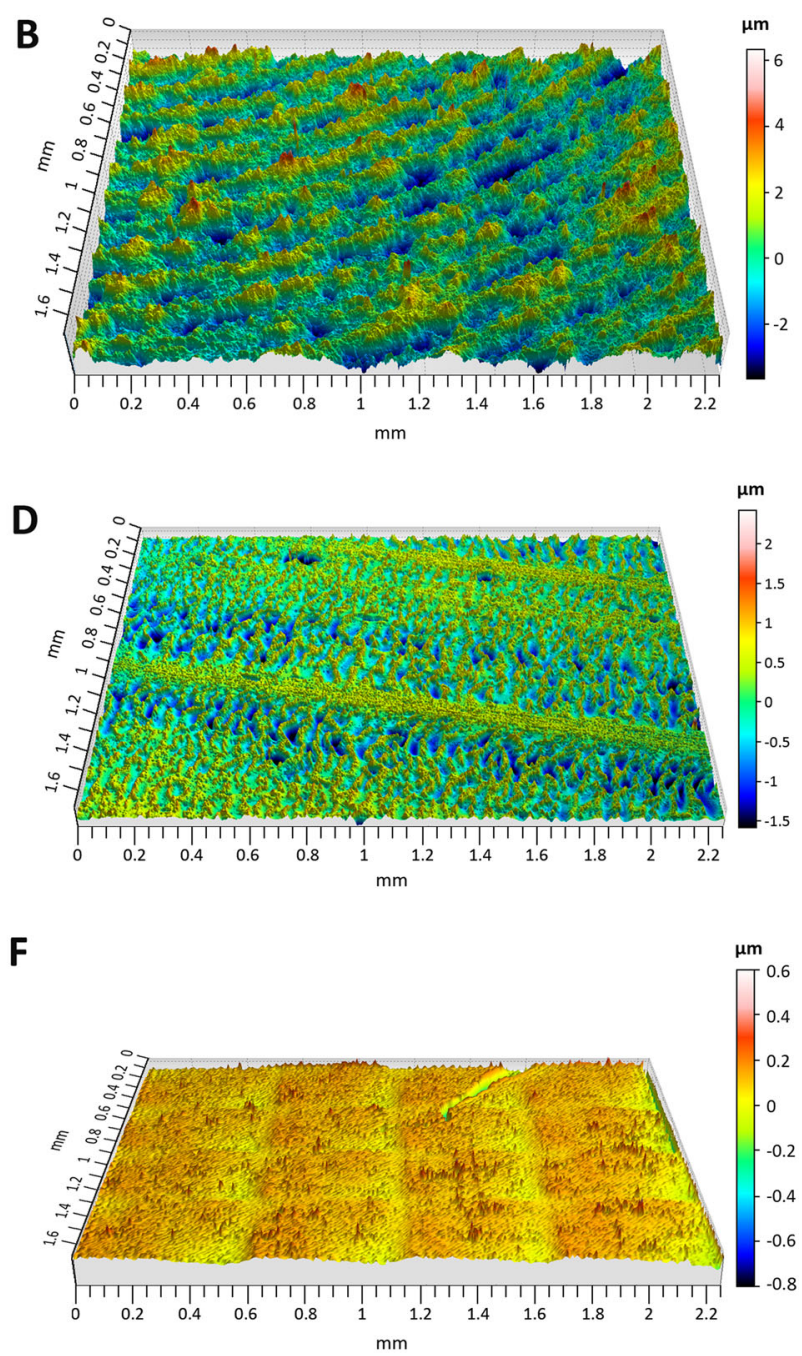

Fig. 5 3D roughness representation of biomaterial surfaces. a Teflon. b Polycarbonate. c Titanium. d Polyurethane. e Silicone. f Borosilicate glass

hydrophobic material, and titanium were where less biofilm developed. According to this fact, Teflon and borosilicate glass were used as comparators for the rest of biomaterials for statistics.
We compared the ratio of the sessile/planktonic logarithm of microorganisms per square centimeter of Teflon, as the concentration and composition of culture media were different. S. epidermidis generated practically the same 
amount of biofilm in a square centimeter of Teflon that staphylococcal planktonic cells suspended in the culture medium (0.92). Similarly, the ratio of sessile and planktonic

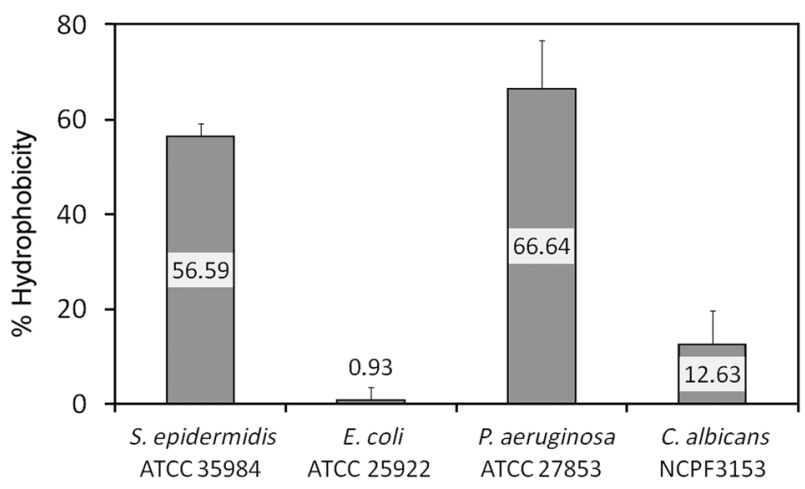

Fig. 6 Microbial surface hydrophobicity

A
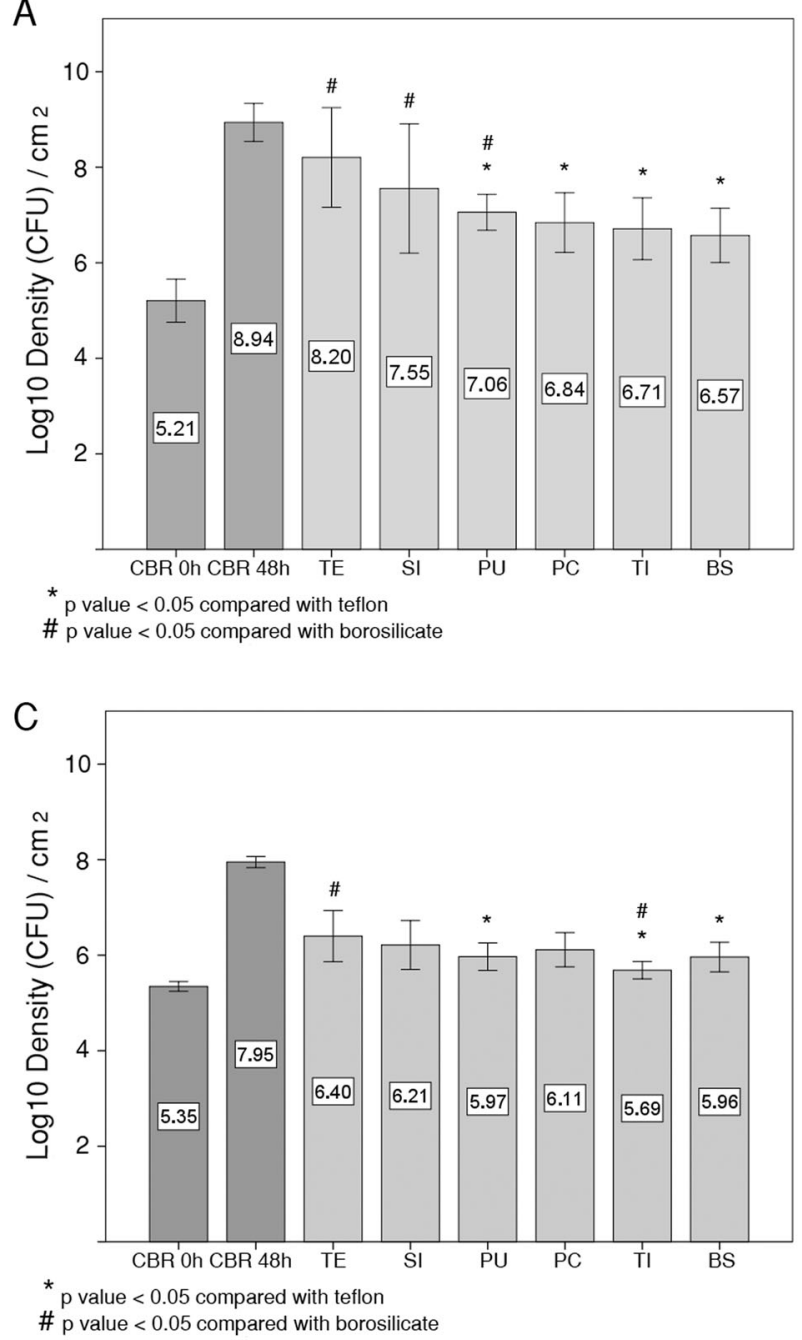

Fig. 7 Biofilm formed after $48 \mathrm{~h}$ of incubation on the different biomaterials. Dark grey bars represent the planktonic growth in the CDC Biofilm Reactor at $0 \mathrm{~h}$ and $48 \mathrm{~h}$. Light grey bars represent the biofilm microorganisms of $P$. aeruginosa was also high (0.93). However, both E. coli and C. albicans showed a lower ratio (0.8 and 0.6 , respectively).

The number of adhering S. epidermidis cells was directly associated with hydrophobicity classification of materials. $S$. epidermidis adhered and developed a more profuse biofilm on Teflon and silicone disks (density $1.6 \times 10^{8} \mathrm{CFU} / \mathrm{ml}$ and $3.6 \times 10^{7} \mathrm{CFU} / \mathrm{ml}$, respectively), the most hydrophobic materials. Biofilms developed on the remaining materials were less profuse $(p=0.000)$ : lesser biofilm was developed on borosilicate, titanium and polycarbonate, materials with lower hydrophobicity, than on Teflon (density $3.75 \times 10^{6}$ $\mathrm{CFU} / \mathrm{ml}, 5.14 \times 10^{6} \mathrm{CFU} / \mathrm{ml}$ and $6.93 \times 10^{6} \mathrm{CFU} / \mathrm{ml}$, respectively). There were no significant differences between biofilms developed in the latter materials $(p>0.450)$ (Fig. 7a).

$E$. coli and $P$. aeruginosa grew under the same conditions and, despite the fact that both bacteria grew similar in

B

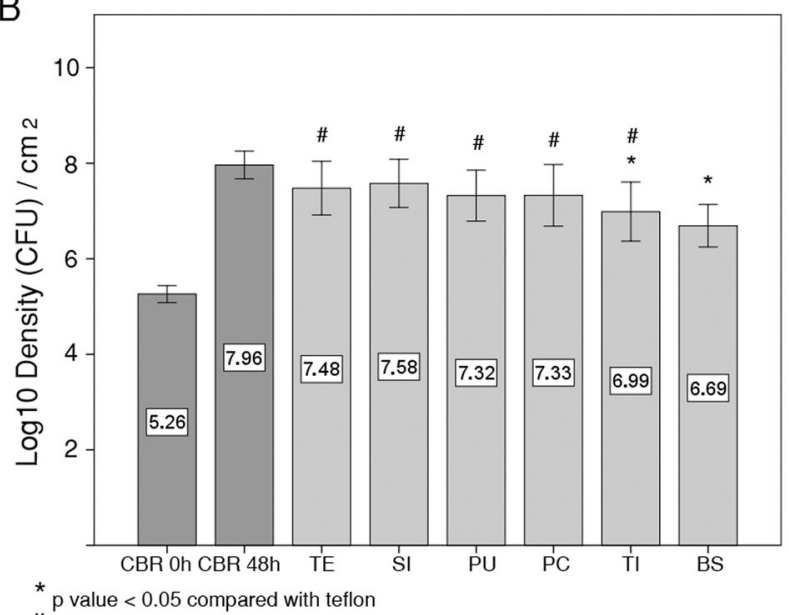

\# $p$ value $<0.05$ compared with borosilicate

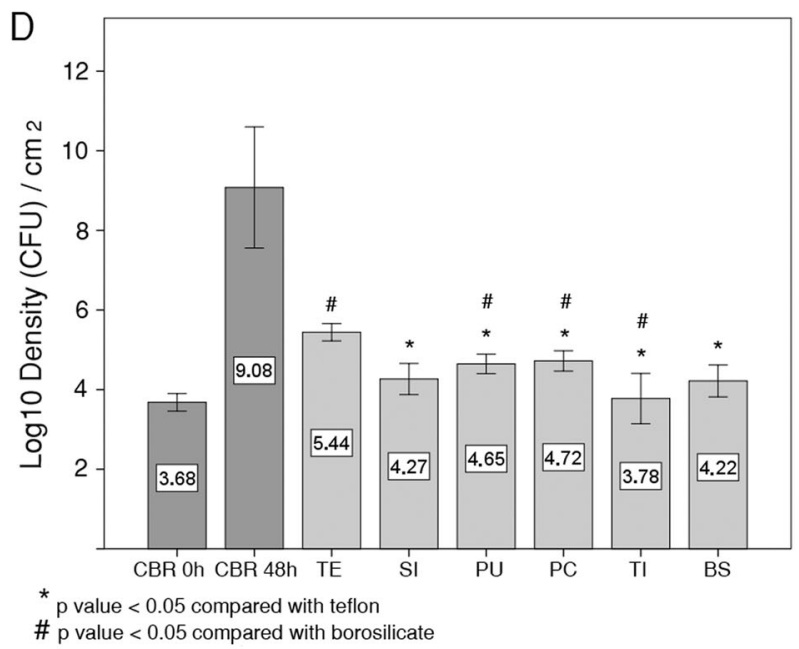

produced by (a) S. epidermidis ATCC 35984. b P. aeruginosa ATCC 27853. c E. coli ATCC 25922. d C. albicans NCPF 3153. Materials were sorted by their hydrophobicity 


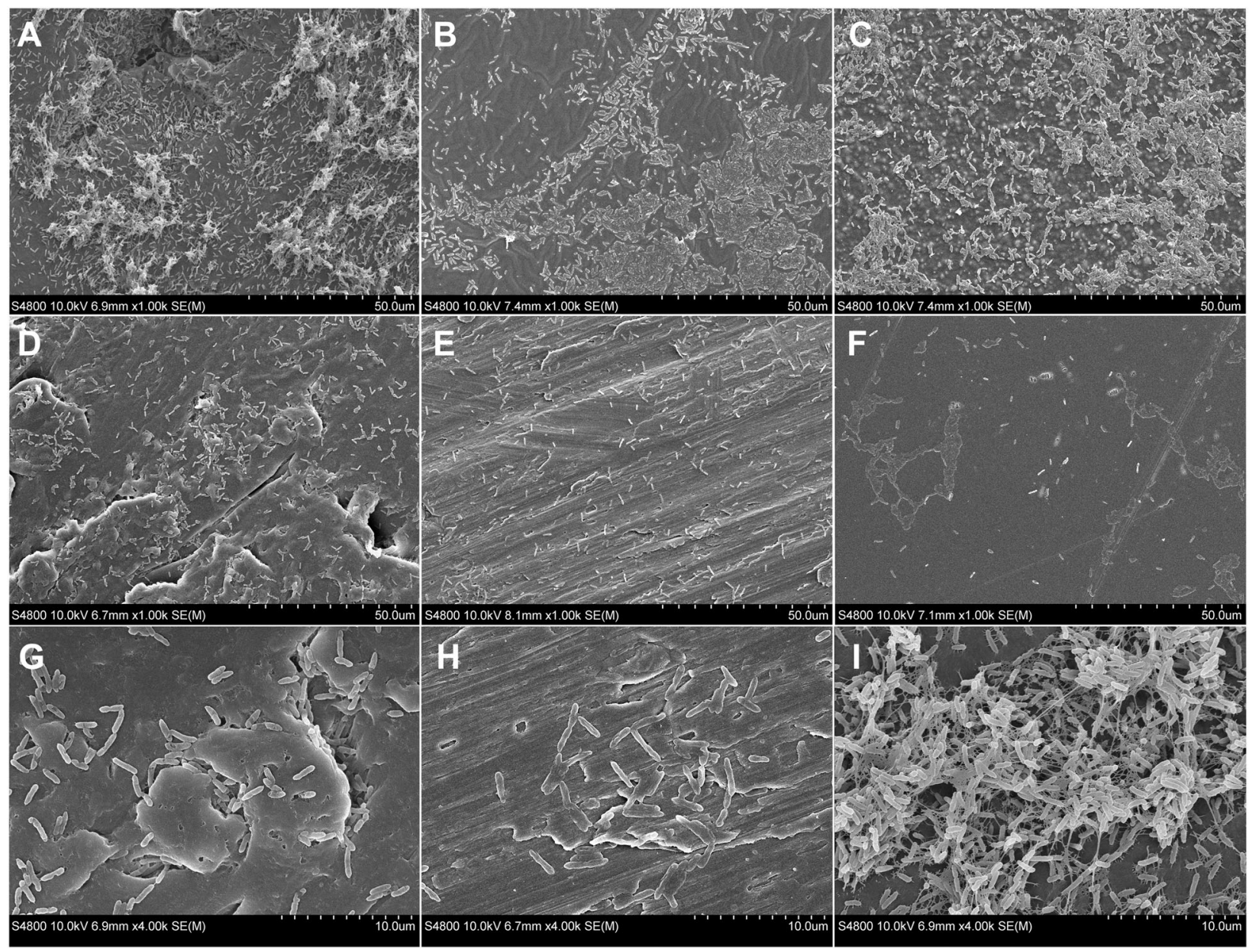

Fig. 8 Scanning electron microscopy of $P$. aeruginosa biofilm at $48 \mathrm{~h}$ on the surface of the six biomaterials: (a) Teflon $(\times 1000)$. b Silicone $(\times 1000)$. c Polyurethane $(\times 1000)$. d Polycarbonate $(\times 1000)$. e

broth $\left(8.91 \times 10^{7} \mathrm{CFU} / \mathrm{ml}\right.$ and $9.12 \times 10^{7} \mathrm{CFU} / \mathrm{ml}$ respectively), $P$. aeruginosa biofilm was denser than that of $E$. coli. P. aeruginosa biofilms were not different between Teflon, silicone, polyurethane and polycarbonate $\left(\approx 3 \times 10^{7}\right.$ $\mathrm{CFU} / \mathrm{ml}, \quad p>0,080$ ), however, biofilm developed on hydrophilic surfaces were smaller $(p<0.006)$. Borosilicate was the biomaterial most resistant to $P$. aeruginosa biofilms $\left(4.9 \times 10^{6} \mathrm{CFU} / \mathrm{ml}, p<0.019\right)$ (Fig. $\left.7 b\right)$. Conversely, titanium was the most resistant to $E$. coli adhesion and biofilm formation $(p<0.001)$. Highest biofilm production was observed on the more hydrophobic biomaterials, Teflon, silicone and polycarbonate disks, without significant differences among them (Fig. 7c). For C. albicans, Teflon is where more biofilm was developed after $48 \mathrm{~h}(p=0.000)$. Likewise, titanium was the most resistant to $C$. albicans biofilm formation despite its roughness $(p<0.012)$, followed by borosilicate glass (Fig. 7d).

SEM images of $P$. aeruginosa biofilms showed a dense microbial cell layer with profuse extracellular matrix on Teflon (Fig. 8a, i). There were also abundant clusters of
Titanium $(\times 1000)$. f Borosilicate glass $(\times 1000)$. g Polycarbonate $(\times 4000)$. h Titanium $(\times 4000)$. i Teflon $(\times 4000)$

biofilms on silicone and polyurethane. However, there were many isolated cells, which appear to be trapped in their cracks and pores, on more hydrophilic materials (Fig. 8g, h).

\section{Discussion}

Some studies have suggested a positive correlation between material roughness and biofilm formation, or have concluded that roughness is a major factor for bacterial adhesion $[17,18]$. Conversely, others suggest that roughness is an insignificant factor [19-21].

In the current study, surface roughness influenced both wettability and biofilm formation in grinded polyurethane disks. Among grinded disks, staphylococcal biofilms was significantly less abundant on disks with a surface roughness average below the diameter of the bacteria $(0.38 \mu \mathrm{m})$ than on disks with larger roughness $(0.51 \mu \mathrm{m}, 1.1 \mu \mathrm{m}$ and $1.9 \mu \mathrm{m})$. Likewise, more abundant biofilm was formed on the most roughly shaped disk. Reduction in bacterial 
adhesion was apparently related to decrease in the availability of surface contact area for interaction.

Interestingly, the unmodified disk without grinding, despite presenting a similar $\mathrm{Sa}$, allowed a higher development of bacterial biofilm than the disks grinded with 4000 grit sandpaper. This apparently paradoxical observation has been previously reported in a study in which an increase of nanoroughness of a titanium surface decreased $S$. epidermidis adhesion compared to unmodified disks [22]. In other study, the number of P. aeruginosa and Staphylococcus aureus adhered cells was reduced by a factor of more than 10 on untreated rough surfaces compared with electropolished smoother surfaces [23]. Disks with less roughness do not always induce less biofilm formation, since not only roughness average (Sa) but different surface topography play important roles in material behavior. An interesting parameter is Ssk, which represents the degree of surface heights symmetry about the mean plane. Ssk indicates predominance of peaks (i.e., Ssk $>0$ ) or valleys $($ Ssk $<0)$. The surface obtained with the 4000 grit sandpaper shows a Ssk superior to 2, whereas in the unmodified surface it is close to -2 , this could explain the differences in the biofilm formation since a roughness (Sa) inferior to the diameter of a bacterium with a prevalence of peaks in its surface involves a decrease of the surface of contact with the bacterium being less likely the adhesion to the material and facilitating its elimination in washes or by a dragging force. Xu and Siedlecki [24] demonstrated that a roughnesscontrolled surface by nanopillars decreased the adhesion of S. epidermidis and S. aureus to polyurethane and inhibited biofilm formation. Reduced wettability and decreased availability of contact area could contribute to a reduction in bacterial adhesion to hydrophobic textured surfaces. In the same way, Vadillo-Rodriguez et al. [25] observed that uniform nanoscale roughness rendered a surface less attractive for staphylococcal adhesion than a smooth one.

Wettability can be affected by factors such as surface topography, chemical nature of liquid, temperature and hydrophobicity or chemical nature of material per se [26]. However, when the droplet is in Wenzel state [27] we can determine the theoretical contact angle $(\theta \mathrm{Y})$ that the material would have if it were completely smooth from the $\mathrm{Sdr}$ parameter. However, when we did this, calculated angles for the four different roughness did not coincide with each other, which may be due to the existence of air bubbles in the material where water did not penetrate, so the Wenzel equation cannot be applied.

Our study found significant biofilm differences in tested range of roughness. This could not be reflected in clinical practice where there are also involved other properties of material, host and microorganism. However, it should be noted that there was not any antimicrobial agent in the material tested: the same material with different Sa ranging from $0.3 \mu \mathrm{m}$ to $2 \mu \mathrm{m}$. For this reason, reducing surface roughness is a factor to be taken into account and may help to inhibit biofilm development and prevention of HAIs to some extent.

Regarding hydrophobicity of bacteria, the results obtained using the CBR are in line with previous studies performed on microtiter plates where microbial strains with higher cell surface hydrophobicity yielded more biofilm [16]. S. epidermidis and $P$. aeruginosa, the species most adherent to hexadecane, developed more abundant biofilms on all disks than $E$. coli and C. albicans with lower hydrophobicity.

Our results suggest that the effect of roughness seems to be surpassed by other properties associated to the studied materials, such as hydrophobicity. For instance, titanium is a material with an intermediate roughness but it was the most resistant to $C$. albicans and E. coli biofilms $(p<0.05)$. $S$. epidermidis biofilm burden did not show significant differences on titanium or borosilicate glass disks, the materials with less biofilm developed. For $P$. aeruginosa, titanium was the second material where less biofilm was observed. Likewise, silicone, presenting a very low roughness, and Teflon, the roughest material, were much more susceptible to bacterial adhesion. Furthermore, the most hydrophobic materials permitted the most abundant biofilm development. Similarly, less abundant biofilms were observed in the most hydrophilic materials, borosilicate and titanium.

Nevertheless, literature is controversial, with reports concluding that roughness is the main factor for microbial adhesion and biofilm development $[17,18,28]$ and studies stating that hydrophobicity is the most influential factor [20, 21]. However, most authors consider both properties, roughness and hydrophobicity, important for adhesion and biofilm formation $[29,30]$ depending their importance on the specific microorganism [31].

Our results regarding S. epidermidis ATCC 35984 are in agreement with those of $\mathrm{Xu}$ et al. [32] who reported that the conversion of hydrophobic polyurethane to a more hydrophilic surface showed a reduction of bacterial biofilm in media containing 25\% human plasma and 50\% TSB. However, there are also evidences indicating that $S$. epidermidis ATCC 35984 is more prone to developing biofilms on hydrophilic surfaces [20, 24, 33]. E. coli ATCC 25922 and $P$. aeruginosa ATCC 27853 showed similar behavior to that of S. epidermidis with increased biofilm formation in hydrophobic materials, such as Teflon or silicone. However, Pontes et al. [34] found that E. coli ATCC 25922 generated the same biofilm regardless of surface hydrophobicity. Andersen et al. [35]. observed a preference of this bacterium for hydrophilic materials. Equally, $C$. albicans showed greater affinity for Teflon confirming the results reported by Frade et al. [36] that tested the same type of polycarbonate and Teflon disks with 10 clinical isolates of $C$. albicans. $\mathrm{Li}$ et al. [37] coated titanium disks with saliva observing a reduction of the 
hydrophobicity of the disks and the subsequently lower biofilm formation after $48 \mathrm{~h}$.

A possible explanation of this diversity of results could be related to multiple factors, such as the methodology used to determine roughness, hydrophobicity and to quantify the biofilm, as well as the strains assayed, the conditions of the culture medium, or the physicochemical properties of the material tested. Therefore, when designing a new material for a biomedical device, the most similar conditions to the actual microenvironment where it is being used should be imitated in the assays to draw sound conclusions.

In conclusion, our results suggest that there is a direct association between surface roughness and the development of staphylococcal biofilm on discs of different roughness. Surface topography influenced bacterial adhesion, regardless of its Sa value. In general, the most hydrophobic materials were those with the highest biofilm formation. On the contrary, titanium and borosilicate glass were the materials most resistant to microbial colonization. This suggests that hydrophobicity is more decisive than roughness in biofilm formation but further studies are needed to confirm these results.

Acknowledgements We thank Dr Francisco José Álvarez and Dr Hector Lafuente from BioCruces Health Research Institute for their excellent technical assistance as well as Dr Ane Miren Zaldua from Leartiker Polymer R\&D for the provision of the polyurethane disks. Our gratitude is extended to the Analytical and High-Resolution Microscopy Service of the Universidad del País Vasco/Euskal Herriko Unibertsitatea (Sgiker) for the SEM imaging. ID-1-P received a scholarship from the ZabaldUz program (Universidad del País Vasco/ Euskal Herriko Unibertsitatea). This work was supported by the Consejería de Educación, Universidades e Investigación of the Gobierno Vasco-Eusko Jaularitza [GIC 15/78 IT-990-16] and the Universidad del País Vasco/Euskal Herriko Unibertsitatea [UFI 11/25].

\section{Compliance with ethical standards}

Conflict of interest We have no specific conflicts of interest related to the current manuscript but declare the following: GQ has received research grants from Astellas Pharma, Pfizer, Merck Sharp \& Dohme, and Scynexis. GQ has served on advisory/consultant boards for Merck, Sharp \& Dohme, and Scynexis, and he has received speaker honoraria from Abbvie, Astellas Pharma, Merck Sharp \& Dohme, Pfizer, and Scynexis. EE has received grant support from Astellas Pharma and Pfizer SLU. The authors have no other relevant affiliations or financial involvement with any organization or entity with a financial interest in or financial conflict with the subject matter or materials discussed in the manuscript apart from those disclosed above.

Publisher's note: Springer Nature remains neutral with regard to jurisdictional claims in published maps and institutional affiliations.

\section{References}

1. Centers for disease control and prevention. hai and antibiotic use prevalence survey. 2018. https://www.cdc.gov/hai/data/portal/ index.html.
2. European Centre for Disease Prevention and Control (ECDC). Annual epidemiological report antimicrobial resistance andhealthcareassociated infections 2014. 2016. http://ecdc.europa.eu/en/publica tions/Publications/antimicrobial-resistance-annual-epidemiologica 1-report.pdf.

3. Percival SL, Suleman L, Vuotto C, Donelli G. Healthcareassociated infections, medical devices and biofilms: risk, tolerance and control. J Med Microbiol. 2015;64:323-34.

4. Palmquist A, Omar OM, Esposito M, Lausmaa J, Thomsen P. Titanium oral implants: surface characteristics, interface biology and clinical outcome. J R Soc Interface. 2010;7:S515-27.

5. Liu X, Huang W, Fu H, Yao A, Wang D, Pan H, et al. Bioactive borosilicate glass scaffolds: improvement on the strength of glassbased scaffolds for tissue engineering. J Mater Sci Mater Med. 2009;20:365-72.

6. Zhang W, Zhang Z, Chen S, Macri L, Kohn J, Yelick PC. Mandibular jaw bone regeneration using human dental cell-seeded tyrosine-derived polycarbonate scaffolds. Tissue Eng Part A. 2016;22:985-93.

7. Seckold T, Walker S, Dwyer T. A comparison of silicone and polyurethane PICC lines and postinsertion complication rates: a systematic review. J Vasc Access. 2015;16:167-77.

8. Desrousseaux C, Sautou V, Descamps S, Traoré O. Modification of the surfaces of medical devices to prevent microbial adhesion and biofilm formation. J Hosp Infect. 2013;85:87-93.

9. del Pozo JL, Rouse MS, Mandrekar JN, Sampedro MF, Steckelberg JM, Patel R. Effect of electrical current on the activities of antimicrobial agents against Pseudomonas aeruginosa, Staphylococcus aureus, and Staphylococcus epidermidis biofilms. Antimicrob Agents Chemother. 2009;53:35-40.

10. Goeres DM, Loetterle LR, Hamilton MA, Murga R, Kirby DW, Donlan RM. Statistical assessment of a laboratory method for growing biofilms. Microbiology. 2005;151:757-62.

11. ASTM E2562-17: Standard test method for quantification of Pseudomonas aeruginosa biofilm grown with high shear and continuous flow using CDC biofilm reactor. 2017. https://www. astm.org/Standards/E2562.htm.

12. Blanquer A, Hynowska A, Nogues C, Ibanez E, Sort J, Baro MD, et al. Effect of surface modifications of Ti40Zr10Cu38Pd12 bulk metallic glass and Ti-6Al-4V alloy on human osteoblasts in vitro biocompatibility. PLoS ONE. 2016;11:e0156644.

13. Sassoni E, Andreotti S, Bellini A, Mazzanti B, Bignozzi MC, Mazzotti C, et al. Influence of mechanical properties, anisotropy, surface roughness and porosity of brick on FRP debonding force. Compos Part B: Eng. 2017;108:257-69.

14. ISO 25178-2:2012. Geometrical product specifications (GPS)surface texture: areal - Part 2: terms, definitions and surface texture parameters. 2012. https://www.iso.org/obp/ui/\#iso:std:iso: 25178:-2:ed-1:v1:en.

15. Rosenberg M, Gutnick D, Rosenberg E. Adherence of bacteria to hydrocarbons: a simple method for measuring cell-surface hydrophobicity. FEMS Microbiol Lett. 1980;9:29-33.

16. Krepsky N, Rocha Ferreira RB, Ferreira Nunes AP, Casado Lins UG, Costa e Silva Filho F, de Mattos-Guaraldi AL. et al. Cell surface hydrophobicity and slime production of Staphylococcus epidermidis Brazilian isolates. Curr Microbiol. 2003;46:280-6.

17. Amoroso PF, Adams RJ, Waters MG, Williams DW. Titanium surface modification and its effect on the adherence of Porphyromonas gingivalis: an in vitro study. Clin Oral Implants Res. 2006;17:633-7.

18. Zaugg LK, Astasov-Frauenhoffer M, Braissant O, HauserGerspach I, Waltimo T, Zitzmann NU. Determinants of biofilm formation and cleanability of titanium surfaces. Clin Oral Implants Res. 2016;27:918-25.

19. Ferreira Ribeiro C, Cogo-Müller K, Franco GC, Silva-Concílio LR, Sampaio Campos M, de Mello Rode S, et al. Initial oral 
biofilm formation on titanium implants with different surface treatments: an in vivo study. Arch Oral Biol. 2016;69:33-9.

20. Koseki H, Yonekura A, Shida T, Yoda I, Horiuchi H, Morinaga Y, et al. Early Staphylococcal biofilm formation on solid orthopaedic implant materials: in vitro study. PLoS ONE. 2014;9: e107588.

21. Jindal S, Anand S, Huang K, Goddard J, Metzger L, Amamcharla J. Evaluation of modified stainless steel surfaces targeted to reduce biofilm formation by common milk sporeformers. J Dairy Sci. 2016;99:9502-13.

22. Puckett SD, Taylor E, Raimondo T, Webster TJ. The relationship between the nanostructure of titanium surfaces and bacterial attachment. Biomaterials. 2010;31:706-13.

23. Wu S, Altenried S, Zogg A, Zuber F, Maniura-Weber K, Ren Q. Role of the surface nanoscale roughness of stainless steel on bacterial adhesion and microcolony formation. ACS Omega. 2018;3:6456-64.

24. Xu LC, Siedlecki CA. Staphylococcus epidermidis adhesion on hydrophobic and hydrophilic textured biomaterial surfaces. Biomed Mater. 2014;9:035003.

25. Vadillo-Rodríguez V, Guerra-García-Mora AI, Perera-Costa D, Gónzalez-Martín ML, Fernández-Calderón MC. Bacterial response to spatially organized microtopographic surface patterns with nanometer scale roughness. Colloids Surf B: Biointerfaces. 2018;169:340-7.

26. Ashokkumar S, Adler-Nissen J, Møller P. Factors affecting the wettability of different surface materials with vegetable oil at high temperatures and its relation to cleanability. Appl Surf Sci. 2012;263:86-94.

27. Peltonen J, Jãrn M, Areva S, Linden M, Rosenholm JB. Topographical parameters for specifying a three-dimensional surface. Langmuir. 2004;20:9428-31.

28. Al-Ahmad A, Wiedmann-Al-Ahmad M, Faust J, Bächle M, Follo M, Wolkewitz M, et al. Biofilm formation and composition on different implant materials in vivo. J Biomed Materi Res Part B: Appl Biomater. 2010;95B:101-9.
29. Zhao B, van der Mei HC, Subbiahdoss G, de Vries J, RustemaAbbing M, Kuijer R, et al. Soft tissue integration versus early biofilm formation on different dental implant materials. Dental Mater. 2014;30:716-27.

30. Gyo M, Nikaido T, Okada K, Yamauchi J, Tagami J, Matin K. Surface response of fluorine polymer-incorporated resin composites to cariogenic biofilm adherence. Appl Environ Microbiol. 2008;74:1428-35.

31. Wassmann T, Kreis S, Behr M, Buergers R. The influence of surface texture and wettability on initial bacterial adhesion on titanium and zirconium oxide dental implants. Int J Implant Dent. 2017;3:32.

32. Xu L, Siedlecki CA. Protein adsorption, platelet adhesion, and bacterial adhesion to polyethylene-glycol-textured polyurethane biomaterial surfaces. J Biomed Mater Res Part B: Appl Biomater. 2015;105:668-78.

33. Tang H, Cao T, Liang X, Wang A, Salley SO, McAllister J, et al. Influence of silicone surface roughness and hydrophobicity on adhesion and colonization of Staphylococcus epidermidis. J Biomed Mater Res Part A. 2009;88A:454-63.

34. Pontes C, Alves M, Santos C, Ribeiro MH, Gonçalves L, Bettencourt AF, et al. Can sophorolipids prevent biofilm formation on silicone catheter tubes? Int J Pharm. 2016;513:697-708.

35. Andersen TE, Kingshott P, Palarasah Y, Benter M, Alei M, Kolmos HJ. A flow chamber assay for quantitative evaluation of bacterial surface colonization used to investigate the influence of temperature and surface hydrophilicity on the biofilm forming capacity of uropathogenic Escherichia coli. J Microbiol Methods. 2010;81:135-40.

36. Frade JP, Arthington-Skaggs BA. Effect of serum and surface characteristics on Candida albicans biofilm formation. Mycoses. 2011;54:e154-62.

37. Li J, Hirota K, Goto T, Yumoto H, Miyake Y, Ichikawa T. Biofilm formation of Candida albicans on implant overdenture materials and its removal. J Dent. 2012;40:686-92. 